\title{
Audit of antenatal steroid use in mothers of preterms admitted to a neonatal inten- sive care unit in Ghana.
}

\author{
Adziri H. Sackey ${ }^{1}$ and Lily G. Tagoe ${ }^{2}$ \\ Ghana Med J 2018; 52(2): 3-7～DOI: http://dx.doi.org/10.4314/gmj.v52i1.2 \\ 'Department of Child Health, School of Medicine and Dentistry, College of Health Sciences, University of
Ghana, Accra, Ghana ${ }^{2}$ Department of Child Health, Korle Bu Teaching Hospital, Accra, Ghana.
}

Corresponding author: Dr Adziri H. Sackey

E-mail: sackey@sky.com

Conflict of interest: None declared

\section{SUMMARY}

Background: Antenatal corticosteroids (ACS) are established as an effective method of reducing preterm morbidity and mortality. At the Korle Bu Teaching Hospital (KBTH), a tertiary referral centre in Ghana, it is recommended that a course of ACS should be given to mothers before delivery between 24 weeks to 34 weeks gestation.

Objectives: The study was performed primarily to determine the level of adherence to guidelines on administration of ACS.

Methods: All babies with gestational ages up to 34 weeks admitted to the neonatal unit (NICU) during the period of the study were eligible for inclusion.

Results: There were 214 eligible admissions during the study period, of which 93 babies (43\%) were studied due to poor access to medical records. Dexamethasone was the only steroid used, and mothers of $65(70 \%)$ of the 93 babies received at least one dose; $17(18 \%)$ received only one dose, $35(38 \%)$ - 2 doses, $9(10 \%)-3$ doses, and $4(4 \%)-4$ doses.

Conclusions: This study has shown a low uptake of antenatal corticosteroids, similar to other low-income and middle-income countries. To improve preterm survival and morbidity, there is an urgent need to increase the use of corticosteroids before preterm deliveries in Ghana and other low-income and middle-income countries.

Funding: Not indicated

Keywords: Antenatal corticosteroids, prematurity, neonatal intensive care, audit, low-income countries.

\section{INTRODUCTION}

Prematurity is recognised as a leading cause of neonatal morbidity and mortality. ${ }^{1}$ Liggins and Howie showed in 1972 that administration of a single course of antenatal corticosteroid to women at risk of preterm delivery resulted in a lower incidence and severity of respiratory distress syndrome, intraventricular haemorrhage and necrotising enterocolitis. ${ }^{2}$ Antenatal corticosteroids (ACS) are now established as an effective and relatively low-cost method of reducing preterm morbidity and mortality. ${ }^{3}$ It is therefore important to monitor uptake of ACS in preterm delivery.

Antenatal steroids increase foetal surfactant production through accelerated development of type 2 pneumocytes, and enhance the neonatal response to postnatal surfactant treatment. ${ }^{4}$ Their use appears to reduce neonatal mortality rate even when infants are born less than 24 hours after the first dose has been given. Reduction in RDS is seen in infants born up to 7 days after the first dose; no reduction in neonatal death, RDS or cerebroventricular haemorrhage is seen in infants delivered more than 7 days after treatment with antenatal corticosteroids. $^{5}$

This study was performed to determine the level of adherence and the impediments to compliance with guidelines on administration of ACS. It is hoped that this knowledge will help improve adherence to the guidelines. Furthermore, to help disseminate improved standards of antenatal and neonatal care, the literature on use of antenatal corticosteroids in low-income and middleincome countries has been reviewed.

\section{METHODS}

The study was based on the neonatal unit (NICU) at the Korle Bu Teaching Hospital and performed in 2 phases: 
from January to March 2015 and from December 2015 to January 2016. The interruption in the study was due to inconsistent availability of staff for prompt identification of newly admitted babies and completion of questionnaires. When babies were recruited some days after admission, instead of immediately after admission, their mothers were more likely to have been discharged, and their case notes were then impossible to retrieve. This resulted in a significant number of otherwise eligible babies not being included in the audit.

The details of all babies admitted to the NICU are routinely entered into a register which, for the purposes of this audit, was inspected on a daily basis. All babies with gestational ages of at most 34 weeks (by dates or examination) who had been admitted to NICU during the period of the study were eligible for inclusion in the study. It is standard practice in the NICU for all admitted babies who were preterm by dates to be assessed by experienced doctors for gestational age using the Ballard scoring system. ${ }^{6}$ Collection of information was standardised by the use of a questionnaire designed for the purpose. In the first phase, paediatric and obstetric residents attached to the NICU identified new admissions and completed these questionnaires by interviewing mothers and by reviewing clinical notes of babies. They also attempted to retrieve and review case-notes of these mothers. In one case where data was unavailable from these sources, it was obtained verbally from mother's obstetrician. Due to difficulties with resident doctors' availability to collect data, the study was suspended until a dedicated research assistant was appointed to restart data collection in the second phase of the study.

Audit standards were based on guidelines in the Department of Obstetrics and Gynaecology manual, KorleBu Teaching Hospital.

The relevant guideline statement was:

A course of ACS should be given to all mothers before delivery between 24 weeks to 34 weeks gestation unless the risk to the mother or foetus outweighs the benefit (chorioamnionitis, acute foetal distress, and acute massive Antepartum haemorrhage). The course is IM Dexamethasone $6 \mathrm{mg} 12$ hourly for 4 doses, or where available, Betamethasone 12mg IM, repeated 24 hours later.

The standards for the study were

1. All mothers of preterm babies less than 34 weeks gestation requiring steroids should have received ACS.

2. All ACS administered should be documented.

3. ACS should be given as IM dexamethasone $6 \mathrm{mg} 12$ hourly for 4 doses or IM betamethasone $12 \mathrm{mg}$ repeated 24 hours later.
4. All patients who do not receive a full course should have acceptable documented reasons.

\section{RESULTS}

The study involved preterm babies admitted to the KBTH NICU with gestations up to 34 completed weeks, from January to March 2015 and from December 2105 to Jan 2016. During these periods there were 214 eligible admissions, of which only 43\% (93 babies) could be studied due to missing case notes. In the first phase, 52 out of 165 eligible babies (32\%) were recruited, and in the second phase, 41 out of eligible 49 babies (84\%).

There were 51 males $(55 \%)$ and $42(45 \%)$ females. Fifty-two babies ( $56 \%$ of the total) were delivered vaginally. Maturity by dates is shown in table 1 . Ten percent of the infants were born before 28 weeks gestation, and $87 \%$ between 28 and 34 weeks.

Table 1 Maturity by dates (MBD) of infants in the study

\begin{tabular}{lll}
\hline MBD & Frequency & Percentage \\
\hline $24-27$ weeks +6 days & 9 & 10 \\
$28-30$ weeks +6 days & 33 & 35 \\
$31-34$ weeks +0 days & 50 & 54 \\
Not entered & $* 1$ & 3 \\
\hline Total & 93 & 100 \\
\hline *Th
\end{tabular}

*The maturity by assessment of this baby was 31 weeks

Birth weights are shown in table 2. Fifty eight percent of infants were less than $1500 \mathrm{~g}$, and $41 \%$ weighed between $1500 \mathrm{~g}$ and $2499 \mathrm{~g}$.

Table 2 Birth weights of the 93 infants in the study

\begin{tabular}{lll}
\hline Birth weight & Number & Percentage \\
\hline$<1000 \mathrm{~g}$ & 9 & 10 \\
$1000-1499 \mathrm{~g}$ & 45 & 48 \\
$1500-1999 \mathrm{~g}$ & 29 & 31 \\
$2000-2499 \mathrm{~g}$ & 9 & 10 \\
$2500-3000 \mathrm{~g}$ & 1 & 1 \\
$\mathrm{~N}$ & 2 & 2 \\
\hline Total & 93 & 100 \\
\hline
\end{tabular}

The commonest indications for preterm delivery were premature rupture of membranes (22\%), hypertensive disorders managed by induction of labour or caesarean section (22\%), and spontaneous preterm labour (11\%). Seventy babies $(75 \%$ of the total) were delivered in KBTH, $20(22 \%)$ in other facilities, and 3(3\%) at home. Maternal ages are shown in table 3. Seven percent of the mothers were less than 21 years old and $4 \%$ older than 40 years. 


\section{Original Article}

Table 3 Maternal ages of infants in the study

\begin{tabular}{lll}
\hline Age & Frequency & Percentage \\
\hline$<18$ years & 3 & 3 \\
18-20 years & 4 & 4 \\
21-25 years & 11 & 12 \\
26-30 years & 33 & 35 \\
31-35 years & 15 & 16 \\
36-40 years & 17 & 18 \\
$>40$ years & 4 & 4 \\
Not document- & 6 & 6 \\
ed & & \\
\hline
\end{tabular}

Total $93 \quad 100$ *

* Rounded up from $98 \%$

Eight (9\% of 93 audited) mothers had a previous preterm delivery. Sixty-five ( $70 \%$ of 93 audited) mothers received antenatal steroids. Dexamethasone was the steroid given in all 65 cases: $17(18 \%$ of 93$)$ received 1 dose, 35(38\%) 2 doses, 9(10\%) 3 doses, and 4(4\%) received 4 doses.

At least $74 \%$ of those who received antenatal steroids had this documented in the mother's clinical notes. It is possible that there were more because in some cases where antenatal corticosteroids were verbally reported to have been given, the mothers' notes were not available. Of those who received less than 4 doses, none had documented reasons as to why a full course of ANC was not given. However, in 20 instances when steroids were not given, on detailed review of maternal notes and discussion with obstetric colleagues -6 arrived in second stage of labour, 5 required emergency caesarean section, 1 was born just before arrival, 1 was a home delivery, and in 7 cases no reason was identified. Table 4 shows performance against the audit standards.

Table 4 Assessing practice against standards

\begin{tabular}{lll}
\hline Standard & $\begin{array}{l}\text { Target } \\
\text { (\%) }\end{array}$ & $\begin{array}{l}\text { \% compli- } \\
\text { ance }\end{array}$ \\
\hline $\begin{array}{l}\text { At least one dose of ACS to } \\
\text { eligible mothers }\end{array}$ & 100 & 70 \\
\hline Full course of ACS given & 100 & 4 \\
\hline $\begin{array}{l}\text { Documentation of any ACS } \\
\text { given }\end{array}$ & 100 & 74 \\
\hline $\begin{array}{l}\text { Documentation of why full } \\
\text { course not given }\end{array}$ & 100 & 0 \\
\hline
\end{tabular}

\section{DISCUSSION}

In this study, $70 \%$ of babies delivered between 24 and 34 weeks gestation received at least one dose of antenatal dexamethasone. This was higher than the $52 \%$ obtained in the WHO Multicountry Survey on Maternal and Newborn Health, performed in 29 countries and involving 7547 women who gave birth at 26-34 weeks' gestation. $^{7}$
Rates of antenatal corticosteroid use varied between countries (median 54\%, range 16-91\%; IQR 30-68\%). ${ }^{7}$ Our rate was also higher than that obtained in a study performed by Gwako G, 2012 in the Kenyatta National Hospital in Kenya, where $46 \%$ of mothers who delivered prior to 34 weeks received antenatal corticosteroids. ${ }^{8}$ Other middle-income countries with low antenatal steroid coverage, compared with this study, include Cameroon (10\%), Brazil (4\%) and Ecuador (35\%). ${ }^{9}$ Pattanittum $\mathrm{P}$ et al reported that $40 \%$ of women who delivered at less than 34 weeks gestation in 9 hospitals in 4 countries in South East Asia, received antenatal corticosteroids. ${ }^{10}$ In Malawi, in a study by Ahlsen et al in two hospitals in the capital, Lilongwe - one district and one tertiary, less than $10 \%$ of the babies studied received any antenatal corticosteroids. ${ }^{11}$ Comparing mothers who received a full course of steroids (4 doses of dexamethasone), we obtained $4 \%$ in this study; Gwafo et al reported 3\% in Kenya ${ }^{8}$; and Ahlsen et al 4\% in Malawi. ${ }^{11}$ Gwafo however inappropriately used the number exposed to antenatal steroids as the denominator for this calculation instead of using the entire study population of 206, which would have resulted in a lower figure of $1 \%$. These results fall far short of our audit standards and the practice in high-income countries. Among those who received antenatal corticosteroids, most had their last injection after 28 weeks gestation (92\%). This was similar to that observed by Pattanittum $\mathrm{P}$ et al in $2008 .^{10}$

The commonest reasons for preterm delivery in our study were spontaneous preterm labour, preterm premature rupture of membranes or hypertension among those who received prenatal steroids. A similar finding was obtained by Gwako $\mathrm{G}$ et $\mathrm{al}^{8}$ and Pattanittum et al. ${ }^{10}$

\section{Dexamethasone versus betamethasone}

Two corticosteroids, dexamethasone and betamethasone, have been shown to be safe and effective in the management of preterm birth. ${ }^{4}$ Roberts et al, after a Cochrane review of 21 studies, concluded that both corticosteroids significantly reduced combined foetal and neonatal death, RDS and cerebroventricular haemorrhage. ${ }^{5}$ Betamethasone however results in a greater reduction in RDS while dexamethasone significantly increased the incidence of puerperal sepsis. ${ }^{5}$ These findings were not in support of an earlier trial by Jobe et al which demonstrated a decreased risk of death with betamethasone but not dexamethasone. ${ }^{12}$ Lee et al also corroborated the findings by Jobe. ${ }^{13}$ The World Health Organisation (WHO) does not express a preference. ${ }^{14}$

Dexamethasone is the antenatal corticosteroid commonly available in Ghana; the price for a $4 \mathrm{mg}$ ampoule ranges from 0.80 to 1.20 Ghana cedis. 
Betamethasone is currently unavailable in the Korle-Bu Teaching Hospital but was available in April 2016 at one private pharmacy at 73 Ghana cedis for a $2 \mathrm{mg}$ ampoule; a course of Betamethasone ( 2 doses of $12 \mathrm{mg}$ ) therefore cost 876 Ghana cedis, compared to about 6 Ghana cedis for Dexamethasone. It is likely that Betamethasone may be obtained at a lower price if purchased in bulk directly by the hospital.

\section{Benefit of ACS in absence of neonatal intensive care} Regarding the widespread use of ACS, cautions have been raised by some studies. Azad et al, after a systematic review of 21 studies in high-income and middleincome country hospitals, concluded that the observed reductions in neonatal mortality rates after antenatal corticosteroids were highly unlikely to be replicated in settings without level 2 neonatal care. They recommended restriction of single-dose antenatal steroids to mothers at " 33 weeks' gestation or less, in preterm labour, and with easy access to good quality, round-the clock level 2 care". ${ }^{15}$ The American Academy of Paediatrics stipulates that level 2 facilities should be capable of delivering continuous positive airway pressure and providing mechanical ventilation for up to 24 hours. They must also have equipment such as portable X-ray machines and blood gas analysers, as well as various personnel such as physicians, specialised nurses, respiratory therapists, radiology and laboratory technicians, who must be available at all times to manage emergencies. ${ }^{16}$ The KBTH NICU is not quite up to level 2 but has level 3 responsibilities, such as the care of babies born at $<32$ weeks' gestation, as well as those weighing less than $1500 \mathrm{~g}$. Azad's concerns seem to have been borne out by the findings of Althabe et al (2015). They reported, in a trial in low and middle-income countries, that increased use of antenatal corticosteroids in low birth weight infants did not decrease neonatal mortality, and that for every 1000 women exposed to this strategy, an excess of 3.5 neonatal deaths occurred, and maternal infection seemed to increase. ${ }^{17}$ However, a significant weakness of this study was the use of low birth weight as a proxy for prematurity, which could result in inappropriate steroid exposure for many pregnancies.

\section{Multiple courses of ACS}

According to current American College of Obstetricians and Gynaecology guidelines (2011), a single rescue course of antenatal corticosteroids may be considered if the gestational age is less than 32 weeks +6 days and the initial course of antenatal steroids was given more than 2 weeks prior and the woman is judged to be likely to give birth within the next week. Regularly scheduled repeat courses or more than two courses are not recommended. ${ }^{18}$

\section{Prediction of imminent delivery}

Accurate prediction of preterm delivery is essential to ensure timely administration of antenatal corticosteroids. In a study by Gyamfi-Bannerman et al in 2016, the following features were considered indicative of a high probability of delivery: spontaneous rupture of membranes; preterm labour with at least $3 \mathrm{~cm}$ dilatation or $75 \%$ cervical effacement; or any other indication for preterm delivery by induction or caesarean section. ${ }^{19}$ Transvaginal ultrasound assessment for cervical length and funnelling is another means of predicting imminent preterm birth.

\section{Limitations of this study}

A limitation of this study is the relatively small study population caused by 1) difficulty in retrieving maternal clinical notes once the mothers were discharged 2) unavailability of some mothers to complete questionnaires and 3) incomplete filling of some of the questionnaires by doctors. These difficulties were later overcome by the use of dedicated data collection personnel who extracted data before maternal discharge. This change resulted in a higher recruitment of eligible cases - 52 out of $165(31.5 \%)$ in the first phase, and 41 out of 49 (84\%) with the help of a research assistant in the second phase. Babies who received antenatal steroids but were delivered after 34 weeks gestation were not included in this study. Also excluded were stillbirths and preterm infants who did not survive long enough to be admitted to NICU.

\section{Conclusion and Recommendations}

The use of antenatal corticosteroids in KBTH compares favourably with data from other low-income and middle-income countries but is far below acceptable levels. The limited data from referring facilities indicates even lower usage of antenatal corticosteroid, and this must be addressed by increasing awareness of health workers of the indications for the use of ACS. This task is rendered more difficult by inaccurate dating of pregnancy due to lack of formal education and poor access to antenatal care. Improving the uptake of ACS is daunting enough but it is only part of the package of measures needed to achieve better neonatal outcomes. For example, the full benefits of ACS may not be realised if the standards of neonatal intensive care are low. Training should be offered to health workers on prediction of preterm delivery to help reduce instances where delivery does not occur after administration of steroids resulting in the need to consider multiple courses of ACS.

To facilitate implementation of the WHO recommendation "that dexamethasone or betamethasone should be available in all maternity facilities and should be included in national essential drugs lists" ${ }^{\text {"13 }}$, we suggest that 
routine documentation of steroid use should be made mandatory in order to facilitate regular audit; health facilities should strengthen their medical records departments and employ research assistants to enable collection of high quality data for monitoring of performance.

\section{ACKNOWLEDGEMENT}

Dr Ozoya, Dr Mustapha and Dr Insaidoo helped with initial questionnaire design and data analysis. The following paediatricians and obstetricians undertook initial data collection: Dr Okaikwei Amartey, Dr L. BatsaNakotey, Dr N. Okai Brako, Dr Agbley Harry Benson, Dr Birikorang, Dr Mensah and Dr Mintah-Yenzu. Dr Samuel Oppong, consultant obstetrician KBTH provided helpful comments on the final manuscript.

\section{REFERENCES}

1. Bhutta ZA and Black RE. Global Maternal, Newborn, and Child Health — So Near and Yet So Far. $N$ Engl J Med. 2013; 369:2226-35 $\mathrm{n}$ engl j med 369;23 nejm.org december 5, 2013

2. Liggins GC, Howie RN. A controlled trial of antepartum glucocorticoid treatment for prevention of the respiratory distress syndrome in premature infants. Pediatrics. 1972; 50(4):515-25.

3. Mwansa-Kambafwile J, Cousens S, Hansen $T$, Lawn JE. Antenatal steroids in preterm labour for the prevention of neonatal deaths due to complications of preterm birth. Int J Epidemiol. 2010 Apr; 39(Suppl 1): i122-i133.

4. Lee M-J, Guinn D, Antenatal corticosteroid therapy for reduction of neonatal morbidity and mortality from preterm delivery, UpToDate. 2015, http://www.uptodate.com/contents/antenatalcorticosteroid-therapy-f...reduction-of-neonatalmorbidity-and-mortality-from-preterm-delivery (Accessed on 16/FEB/2016)

5. Roberts D, Dalziel SR. Antenatal corticosteroids for accelerating fetal lung maturation for women at risk of preterm birth. Cochrane Database Syst Rev 2006;3:CD004454.

6. Ballard JL, Khoury JC, Wedig K, Wang L, EilersWalsman BL, Lipp R. New Ballard Score, expanded to include extremely premature infants. J Pediatrics. 1991 Sep; 119(3): 417-423.

7. Vogel JP, Souza JP, Gülmezoglu AM, Mori R, Lumbiganon P, Qureshi Z et al. Use of antenatal corticosteroids and tocolytic drugs in preterm births in 29 countries: an analysis of the WHO Multicountry Survey on Maternal and Newborn Health. The Lancet. 2014; 384(9957): 1869-1877

8. Gwako G, Qureshi ZN, Kudoyi W, Were F. Antenatal corticosteroid use in preterm delivery at Ken- yatta National Hospital, J Obstet Gynaecol East Cent Africa. 2013; 25(1): 3-9

9. Liu G, Segrè J, Gülmezoglu AM, Mathai M, Smith $\mathrm{JM}$, Hermida $\mathrm{J}$ et al. Antenatal corticosteroids for management of preterm birth: a multi-country analysis of health system bottlenecks and potential solutions, BMC Pregnancy Childbirth. 2015; 15(Suppl 2): S3

10. Pattanittum P, Ewens MR, Laopaiboon M, Pisake Lumbiganon, McDonald SJ, Crowther CA, Use of antenatal corticosteroids prior to preterm birth in four South East Asian countries within the SEAORCHID project, BMC Pregnancy Childbirth. 2008; 8: 47

11. Ahlsen AK, Spong E, Nomsa K, Kamwendo F, Wolff K, Born too small: who survives in the public hospitals in Lilongwe, Malawi?, Arch Dis Child Fetal Neonatal Ed. doi:10.1136/archdischild-2013305877

12. Jobe AH, Soll RF. Choice and dose of corticosteroid for antenatal treatments. Am J Obstet Gynecol. 2004; 190:878.

13. Lee BH, Stoll BJ, McDonald SA, Higgins RD. Adverse neonatal outcomes associated with antenatal dexamethasone versus antenatal betamethasone. Pediatrics. 2006; 117:1503

14. Hofmeyr GJ. Antenatal corticosteroids for women at risk of preterm birth: RHL commentary (last revised: 2 February 2009). The WHO Reproductive Health Library; Geneva: World Health Organization.

15. Azad K, Costello A. Extreme caution is needed before scale-up of antenatal corticosteroids to reduce preterm deaths in low-income settings. Lancet Glob Health. 2014;(2):e191-192

16. Committee on Fetus and Newborn, Levels of Neonatal Care, Paediatrics. 2012; 130:587-597

17. Althabe F, Belizán JM, McClure EM, HemingwayFoday J, Berrueta M, Mazzoni A et al, A population-based, multifaceted strategy to implement antenatal corticosteroid treatment versus standard care for the reduction of neonatal mortality due to preterm birth in low-income and middle-income countries: the ACT cluster-randomised trial, The Lancet. 2015, 385(9968): 629-639

18. American College of Obstetricians and Gynaecologists (ACOG) Committee on Obstetric Practice, Obstet Gynecol. 2011 Feb; 117(2 Pt 1): 422-424

19. Gyamfi-Bannerman C, Thom EA, Blackwell SC, Tita ATN, Reddy UM, Saade GR et al, Antenatal Betamethasone for women at risk for late preterm delivery $N$ Engl $J$ Med. 2016 Feb, DOI: 10.1056/NEJMoa1516783 (Accessed on 10/FEB/2016) 